\title{
Effects of Wood Properties on the Behaviors of Wood Particle Reinforced Polymer Matrix Composites
}

\author{
M. R. Hossain*, M. F. Hossain, and M. A. Islam \\ Materials and Metallurgical Engineering, Bangladesh University of Engineering and Technology, \\ Dhaka, Bangladesh
}

Received 24 July 2013, accepted in final revised form 7 August 2014

\begin{abstract}
Polymer matrix composites, reinforced with various types of particles are being widely used to reduce the overall weight of structures because of their good combination of various properties such as high strength to weight ratio, good fatigue properties, corrosion resistance, etc. However, most of the polymeric materials are not bio-degradable. As a result, demands of natural fiber reinforced composites are increasing day by day. Considering this, initiative was taken to develop wood saw dust particles reinforced polymer (unsaturated polyester) matrix composites with varying proportions ( 5 and $10 \%$ by weight $[\mathrm{w} / \mathrm{w}]$ ) of various wood saw dust particles. The developed composites were characterized by means of Tensile Test, fractography of the broken tensile test samples and water absorption test. Experimental results exhibited that addition of wood particles decreases the tensile strength of the composites and that, for higher strength wood, the degradation of the tensile strength of the composites is minimized. Addition of wood particles increases the water absorption of the composites. Water absorption of both pure polyester and wood particle reinforced composites has been found to increase with increase in time. However, the overall water absorption behaviors of the composites are dependent on the density of the wood used.
\end{abstract}

Keywords: Polymer matrix composites; Wood saw dust; Reinforcement; Particles size; Tensile properties; Water absorption.

@ 2014 JSR Publications. ISSN: 2070-0237 (Print); 2070-0245 (Online). All rights reserved. doi: http://dx.doi.org/10.3329/jsr.v6i3.15811 J. Sci. Res. 6 (3), 431-443 (2014)

\section{Introduction}

Wood is a combination of cellulose fiber and lignin. The cellulose fiber provides strength and the lignin is the "glue" that bonds and stabilizes the fiber. With the growing economic competition and the ecological pressure, the past decade has seen a renewed interest in

\footnotetext{
* Corresponding author: hrashnal@hotmail.com
} 
developing more efficient reinforcements along with overall production cost. Cellulose based fibers are relatively cheaper and can meet many requirements for making the products to be economical. They are made from natural resources and thus add biodegradability to plastics [1]. This biodegradable property ushered a new horizon in the field of polymer matrix composites reinforced with various natural fibers. The utilization of ligno-cellulosic materials in the production of polymeric composites is attractive particularly because of low cost/high volume applications. Bio-degradable ligno-cellulosic fillers possess several advantages compared to inorganic fillers, such as lower density, greater deformability, lower abrasiveness and cost [2, 3]. Short-fiber, i.e. wood sawdust reinforced polymeric composites has gained importance due to considerable processing advantages. However, natural fibers have also many drawbacks. The main problem of wood saw dust particles is their hygroscopic behavior, which weaken particle-polymer inter-bonding and quality changes with time [4]. However, wood fibers show acceptable mechanical properties such as tensile strength and Young's moduli [5-7].

Composites are possible to develop with minimal overall production cost by embedding waste wood particles from other manufacturing processes or recycled materials in polymer. It has been observed that about $5-11 \%(w / w)$ of the total log woods become wastage in the forms of saw dust, chips or flakes during the time of wood processing $[8,9]$. Development of composites with utilization of these waste woods could be a potential option for producing natural fiber reinforced composites. Because of various attractive properties, polymer composites filled with natural ligno-cellulosic fibers have attracted the attention of many researchers and technologists. As a result, both polymer matrices and natural filler systems have been widely investigated [10]. As a matter of fact, Oksman and Lindberg [11] as well as the team of Liao et al. [12] studied the mechanical behavior of composites based on polyethylene and wood flour samples. On the other hand, Zaini et al. [13] and Kaci et al. [14] investigated the mechanical behaviors of polypropylene/wood flour composites. Some authors examined also the mechanical behaviors of various polymer based wood flour reinforced composites [15, 16].

Improvement in mechanical and physical properties have resulted interest in wood saw dust polymer matrix composite materials in many industrial applications, including light weight, high strength parts for the automotive and aerospace industries, containers, sporting goods, thermal and electrical insulators, switch boards, circuit boards, etc. Many studies have been published concerning the properties and processing conditions of various composites reinforced with wood fibers/particles. However, a very little information is available on the effects of wood properties (especially the woods available in Bangladesh) such as density and strength on the properties of polymer based composites. The current study deals with the evaluation of the mechanical and physical properties of unsaturated polyester filled wood saw dust (different trees as Garjan, Kerosene and Gamari) composite materials. 


\section{Experimental}

\subsection{Materials}

The matrix was unsaturated polyester resin and the reinforced material was wood saw dust particles obtained from sawing of Garjon (Dipterocarpus Turbinatus Gaertn), Kerosene (Cordia Subcordata) and Gamari (Gmelina Arborea) woods. The saw dusts thus produced were screened to get particles up to $250 \mu \mathrm{m}$ size by sieve.

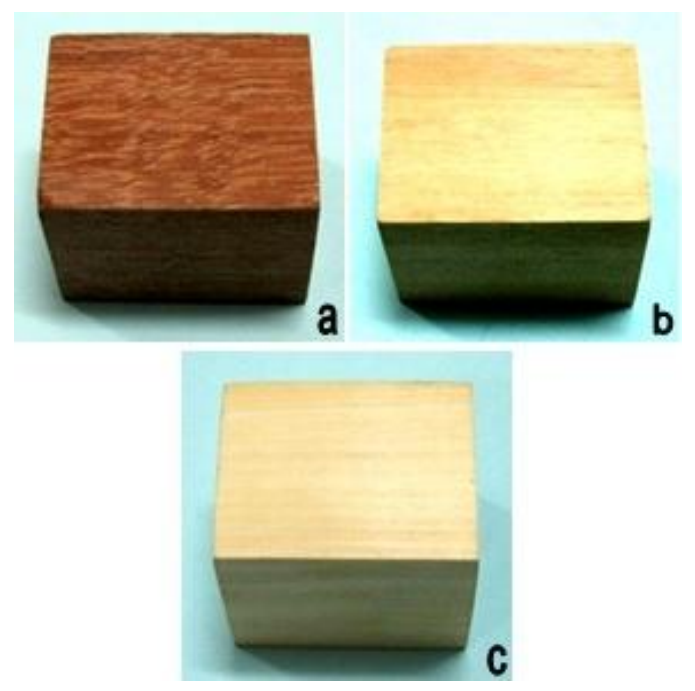

Fig. 1. Rectangular blocks of three different woods (a) Garjan, (b) Kerosene and (c) Gamari.

\subsection{Density measurement of wood}

For measuring densities of different woods, the volumes and weights of the rectangular solid wood blocks (Fig. 1) were measured. In order to know the apparent density $\left(\rho_{\mathrm{A}}\right)$ of various woods the following equation was used.

$$
\rho_{A}=M / V
$$

where, $M$ is the mass and $V$ is the volume of wood block.

For true density $\left(\rho_{\mathrm{T}}\right)$ measurement, wood saw dust particles were used. In this case, pycnometer technique (Fig. 2) was used by employing the following equation.

$$
\rho_{T}=\frac{W-P}{\left(W_{1}-P\right)-\left(W_{2}-W\right)} \times \rho_{W}
$$


where, $P$ is the mass of empty pycnometer, $W, W_{1}, W_{2}$ and $\rho_{\mathrm{W}}$, respectively, are mass of pycnometer with fine particles, with water and with both wood particles and water and density of water. The apparent and true densities of different woods are given in Table 1.

Table 1. Densities of polymer and saw dusts used.

\begin{tabular}{ccc}
\hline Materials & $\rho_{\mathrm{A}}(\mathrm{g} / \mathrm{cc})$ & $\rho_{\mathrm{T}}(\mathrm{g} / \mathrm{cc})$ \\
\hline Polyester & - & 1.04 \\
\hline Garjon & 0.74 & 1.30 \\
\hline Kerosene & 0.46 & 1.12 \\
\hline Gamari & 0.38 & 0.86 \\
\hline
\end{tabular}

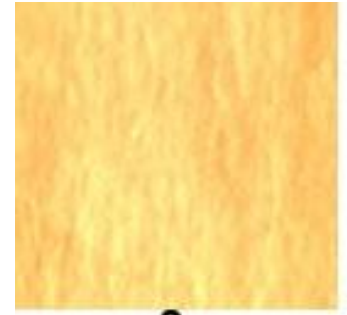

a

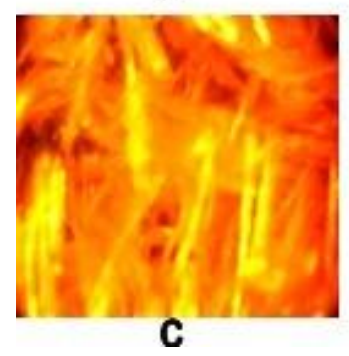

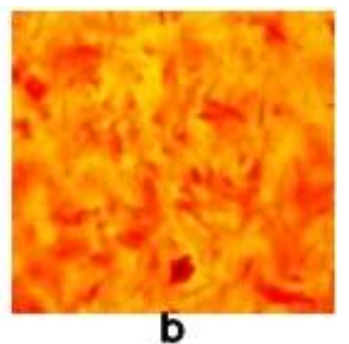

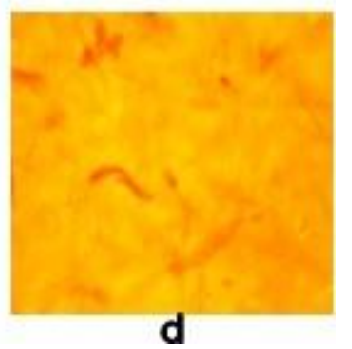

Fig. 2. Macrographs of moulded (a) polyester and (b) Garjan, (c) Kerosene, and (d) Gamari reinforced composites (X20).

\subsection{Compounding and moulding}

The composite mixtures of polyester with saw dust particles (5 and 10\% [w/w]) were prepared directly in a beaker for about 5 minutes. Before casting of the composite mixtures into moulds, vacuum-degassing was carried out for about 12 minutes to remove bubbles or any sort of dissolved gases inside the mixtures. After vacuum-degassing peroxide (methyl ethyl ketone peroxide [MEKP hardener]) was mixed with the polyestersaw dust mixture. At last stage, the mixture was taken for degassing for another 2 minutes. The paste was filled in a metal mould $(114 \mathrm{~mm} \times 7 \mathrm{~mm} \times 6 \mathrm{~mm})$ for tensile strength measurement and then machined to get standard ASTM (American Society for Testing 
and Materials) tensile test samples. In other batches, mixtures prepared by following the above mentioned procedure were filled in a mould of dimensions $100 \mathrm{~mm}$ diameter and $10 \mathrm{~mm}$ thickness for making water absorption test specimens. Each sample was cured at room temperature for 24 hours. The microstructures of the developed composites are shown in Fig. 2.

\subsection{Tensile test}

Tensile samples of each group were used to determine their tensile properties. The tensile test was performed in Instron Universal Testing Machine at a cross-head speed of 2 $\mathrm{mm} / \mathrm{min}$ according to ASTM D3039 standard (rectangular specimens). The size of the specimen was $110 \times 6 \times 6 \mathrm{~mm}^{3}$

\subsection{Fractography of tensile test samples}

After Tensile Test, fracture surfaces were cut for fractography analysis under the SEM. The electrical conductivity of all test samples used in this research project was very poor. So, the fracture surfaces of all samples were gold coated by sputtering to make the fracture surfaces electrically conductive. For fractography analysis, $15 \mathrm{kV}$ accelerating voltage was used.

\subsection{Water absorption test}

Water absorption test of the developed composites was carried out according to ASTM D570 at ambient temperature. For doing this, specimens were immersed in water bath for four weeks at ambient temperature. After a week, these samples were taken out from the water bath and water was wiped off by tissue paper on both sides of the surfaces and reweighed. Again, these test samples were re-immersed in the water bath. In this way, next three weeks measurements were carried out after every week. The percentage of the water absorption (A) was calculated from the following equation:

$$
A(\%)=\frac{M_{W}-M_{d}}{M_{d}} \times 100
$$

where, $M_{w}$ and $M_{d}$ are, respectively, mass of samples in wet and dry conditions.

\section{Results and Discussion}

\subsection{Density}

Both the apparent and true densities of all woods are presented in Table 1. From this table, it is clear that density of Garjon wood is the highest (both apparent and true densities) and that of Gamari is the lowest. This table also reveals that true densities of all woods are 
higher compared to the corresponding apparent densities. The reason is that apparent density was measured using rectangular blocks of wood, which contained a lot of lignin associated pores. On the other hand, fine saw dust particles were used for true density measurement. In this case, influence of pores on density became negligible. So, the true densities of all woods were significantly higher. The true densities of Garjon and Kerosene are 1.3 and $1.12 \mathrm{~g} / \mathrm{cc}$ respectively, which are higher than the density of water (1 $\mathrm{g} / \mathrm{cc}$ ). Because of this, Garjon and Kerosene wood particles settled down at the bottom level of the pycnometer during density measurement, Fig. 3. On the other hand, the true density of Gamari wood is $0.86 \mathrm{~g} / \mathrm{cc}$. As the true density of Gamari wood is lower than unity, i.e. lower than the density of water, the wood particles floated above the water level in the pycnometer.
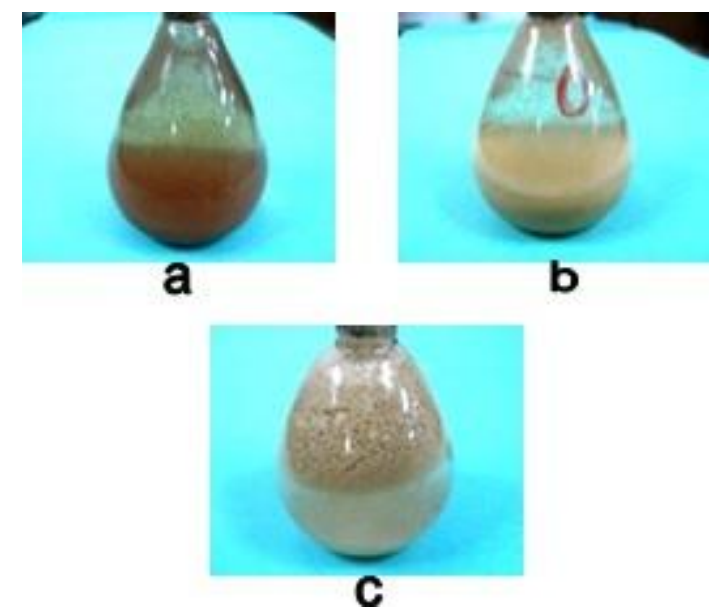

Fig. 3. Settled and floated wood particles during true density measurement of various woods a) Garjan, b) Kerosene and c) Gamari.

\subsection{Tensile test}

\subsubsection{Tensile strength of pure woods}

Table 2. Tensile properties of various woods.

\begin{tabular}{lc}
\hline Materials & Tensile strength (MPa) \\
\hline Garjon & 125 \\
Kerosene & 85 \\
Gamari & 64 \\
\hline
\end{tabular}


From Table 2, it is clear that Garjon wood resulted in the highest strength and Gamari showed the lowest. In this respect, there is relationship between densities of woods. As the density increased, the strength of the wood also increased (Tables 1 and 2).

\subsubsection{Tensile strengths of composites}

The effects of proportions of wood saw dust particles on tensile strength of the developed composites are presented in Table 3. From this table, it is revealed that Garjon wood particle reinforced composites showed the highest strength and the Gamari wood particle reinforced composites showed the lowest strength. In the previous section, the strength of Garjon wood has been found to be the highest and strength of Gamari has been found to be the lowest. This table clearly indicates that wood strengths have noticeable effects on the composite strengths. Wood particle of higher strength wood resulted higher strength. The possible reason behind the higher strength wood reinforced wood particle composites is that during tensile loading, higher strength wood particle showed more rigidity and acted as more powerful barriers for easy crack formation. On the other hand, inter particle separation between soft wood particle is easier, i.e. crack formation between wood particle/polyester matrix interfaces or inside wood particle is easier in the case of soft wood particle reinforced composites. Once crack is formed, the composites become unstable and fail catastrophically. So, soft wood particle reinforced composites showed relatively lower strength [17].

Table 3. Tensile strength of pure polyester and wood particle reinforced composites with various proportions of wood particles.

\begin{tabular}{lccc}
\hline Sample ID & \multicolumn{3}{c}{ Tensile strength of composites (MPa) } \\
\cline { 2 - 4 } & $10 \%$ & $5 \%$ & $0 \%$ \\
\cline { 2 - 4 } Pure polyester & - & - & 43 \\
Garjon reinforced & 24 & 29 & - \\
Kerosene reinforced & 22 & 25 & - \\
Gamari reinforced & 20 & 22 & - \\
\hline
\end{tabular}

From Table 3, it is also clear that addition of wood particles decreased the strength of the composites and with increase in the proportion of wood particle, the strengths of all composites further decreased gradually. With the increase in the proportion of wood particle, their uniform mixing and distribution inside the matrix becomes difficult and clusters (stacking) of wood particle are formed at various locations of the developed composites. As cluster of wood particle has no or little bonding strength within itself, it behaves a weak point in the composites and cracks are formed easily during tensile test. 
So, the composite strength gradually decreased with increase in the proportions of the wood particles. Similar observation has also been made by other researchers [18-20].

\subsection{Fracture morphology}

After Tensile Test of pure polyester and wood particle reinforced composite samples, the fracture surfaces were cut carefully to observe various fracture features under scanning electron microscope (SEM). In the case of for pure moulded polyester, brittle type fracture mode was observed, Fig. 4. On the fracture surfaces, some micron size particles (marked by circles) were observed. These particles possibly were foreign dust particle picked up during moulding of the polyester or its production period. For some tensile samples of pure polyester, fracture was found to initiate from these foreign dust particle, Fig. 5. After nucleation of the crack around several dust particle (marked by circle) existing voids created due to dissolved air, it was propagated towards outer surfaces (marked by arrows).

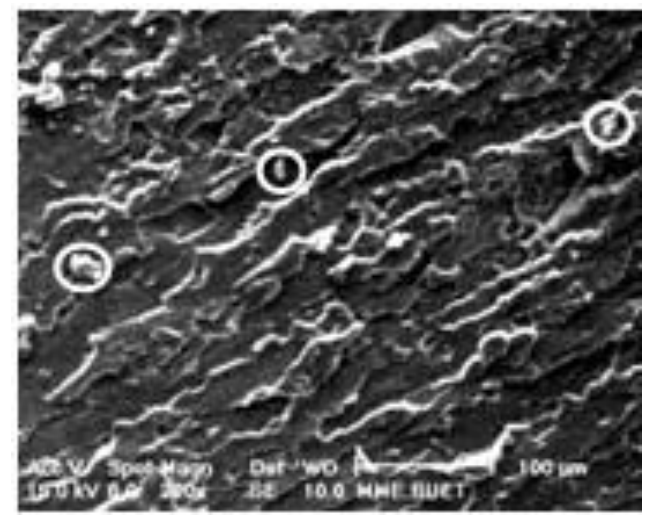

Fig. 4. SEM micrograph showing brittle type fracture surface of pure polyester.

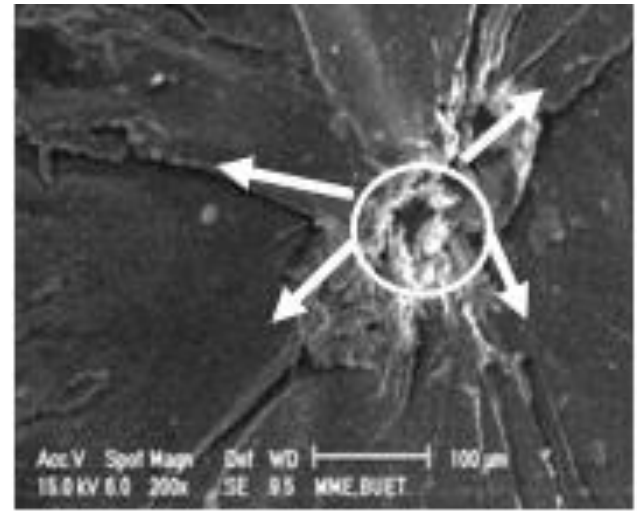

Fig. 5. SEM micrograph showing fracture initiation site around dust particles in pure polyester. 
For all moulded composites, addition of $5 \%$ wood particle resulted better distribution of wood particles. However, bubbles were formed by dissolved air, Fig. 6. With increase in the proportion of wood particle, tendency of wood stacking became visible, Fig. 7. This type of wood stacking along with bubbles has been thought to be responsible to reduce the strength of the wood particle reinforced composites. The dominating role of air bubbles in crack formation is very clear from the presence of secondary internal cracks around the air bubble, Fig. 8. This observation suggests that the level of vacuum treatment used the moulding of the composites was not sufficient and that adequate vacuum might improve the strength of the developed composites.

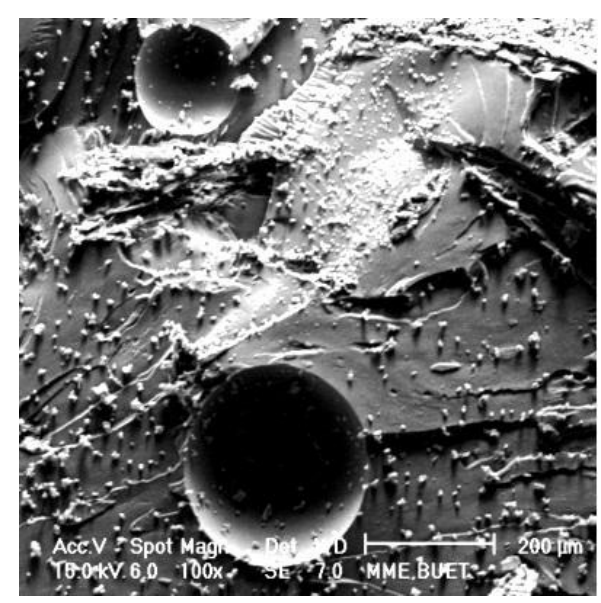

Fig. 6. SEM micrograph showing the distribution of wood particles and air bubbles in $5 \%(w / w)$ wood particle reinforced polyester composite.

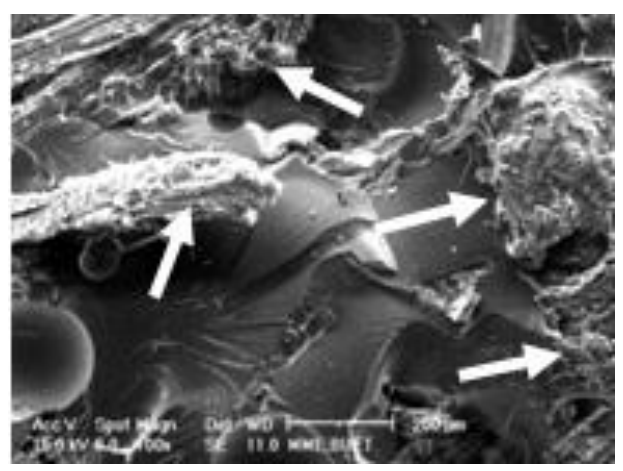

Fig. 7. SEM micrograph showing the distribution of wood particles and air bubbles in $10 \%(w / w)$ wood particle reinforced polyester composite. 


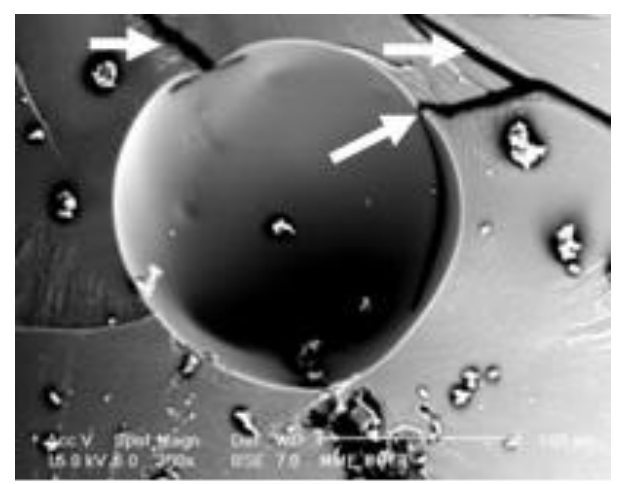

Fig. 8. SEM micrograph showing the gas bubble associated secondary cracking (marked by arrows in $10 \%(\mathrm{w} / \mathrm{w})$ wood particle reinforced polyester composite.

It has been mentioned that addition of wood particle caused more air bubbles in the composite and the air bubbles played important role to nucleate early crack during tensile test. This behavior subsequently reduced the composite strength. The dominating behavior of air bubbles in crack formation is very clear from the presence of secondary internal cracks around the air bubble, Fig. 8. This observation suggests that the level of vacuum treatment used the moulding of the composites was not sufficient and that adequate vacuum might improve the strength of the developed composites.

\subsection{Water absorption}

After calculation of percentage of water uptake of the wood particles reinforced composites, $\%$ of water absorptions versus conditioning periods were plotted, which are illustrated in Figs. 9 and 10.

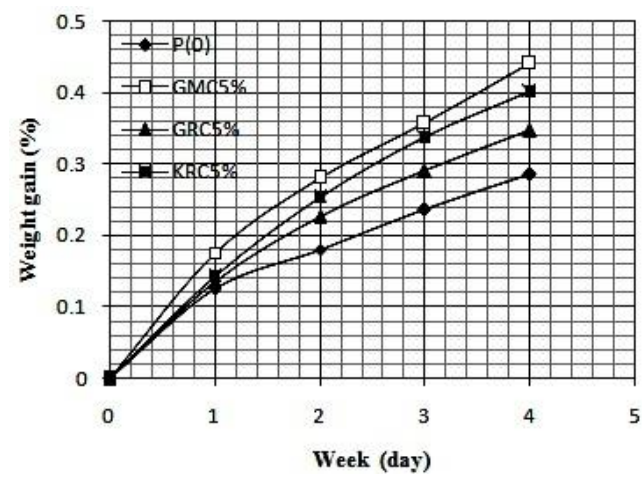

Fig. 9. Water absorption behaviors of composites with 5\% (w/w) wood saw dust particles. Note: P, GMC, GRC and KRC, respectively, denote pure polyester, composites of Gamari, Garjan and Kerosene wood particles. 
From these figures, it is clear that pure polyester has lower water absorption tendency and that with increase in the wood particle content increased the water absorption tendency. This observation is true for all woods and their particle size used for this work. All natural fibers/particle have a tendency to absorb water and possess low wet ability by hydrophobic resins due to presence of hydrophilic hydroxyl groups of cellulose, hemicellulose and lignin. Hemicellulose is mainly responsible for the moisture absorption in composites.

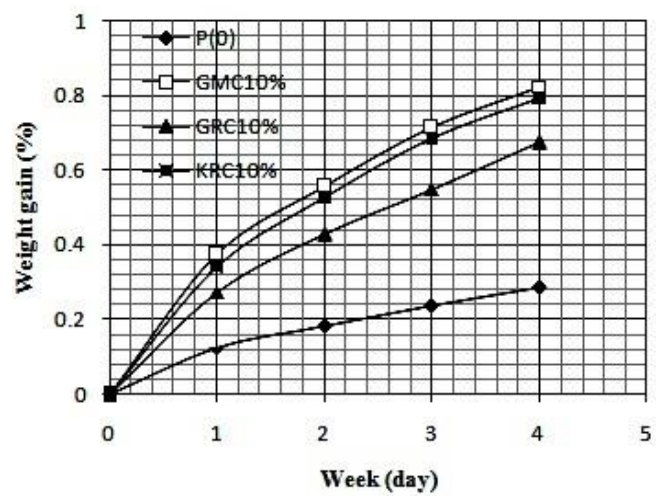

Fig. 10. Water absorption behaviors of composites with $10 \%(\mathrm{w} / \mathrm{w})$ wood saw dust particles of various woods.

Non-crystalline cellulose and lignin also play an important role in water uptake process. Absorption of water in composites causes swelling of fiber till the cell walls are saturated with water and beyond that water exists as free water in the void structure leading to composites delamination or void formation. Absorbed water causes weakening of interfacial adhesion and hydrolytic degradation of both matrix and fiber [21- 24]. Cracking and blistering of fiber cause high water absorption, while degradation causes leaching of small molecules [25]. With increase in the wood particle content and time period, the total water intake also increased. So, the overall water absorption of the composites increased with wood particle content as well as with time period [19,21].

\section{Conclusion}

Following conclusions are made from this research work:

a. Among three (Garjon, Kerosene and Gamari) woods, Garjan resulted the highest and Gamari resulted the lowest tensile strengths. Experimental results of similar trends of density values suggested the dependency of wood strength on its density.

b. For all cases, tensile strengths of composites were found to decrease with increase in the wood particle contents. This type degradation in tensile strength of the 
composites was due weak points formation related with either wood particle stacking or air bubbles formed during moulding process of composites.

c. Tensile strengths of wood particle reinforced composites were found to depend on parent wood strengths. In this case, particles of higher strength wood results relatively better tensile strengths.

d. Higher density wood causes less water absorption, and that water absorption has been found to increase with the proportion of wood particle content.

\section{References}

1. A. K. Bledzki and O. Faruk, Appl. Sci. Manufact. A 37, 1358 (2006). http://dx.doi.org/10.1016/j.compositesa.2005.08.010

2. S. Takase and N. Shiraishi, J. Appl. Polym. Sci. 37 (2), 645 (1989). http://dx.doi.org/10.1002/app.1989.070370305

3. J. M. Felix and P. Gatenholm, J. Appl. Polym. Sci. 42 (1), 609 (1991). http://dx.doi.org/10.1002/app.1991.070420307

4. O. M. Terciu, I. Curtu, C. Cerbu, and G. I. Stan, Proc. 8th Intern. Conf. Wood Science and Engineering (ICWSE), (Brasov, Romania, 2011) pp. 345-352, ISSN 1843-2689.

5. M. R. Hossain, M. A. Islam, A. V. Vuure, and I. Verpoest, J. Sci. Res. 5 (1), 43 (2013). http://dx.doi.org/10.3329/jsr.v5i1.10519

6. J. Bhaskar, S. Haq, and S. B. Yadaw, J. Thermopl. Comp. Mater. 25 (4), 391 (2012).

7. C. A. S. Hill and H. P. S. A. Khali, J. Appl. Polym. Sci. 78 (1),1685 (2000). http://dx.doi.org/10.1002/1097-4628(20001128)78:9<1685::AID-APP150>3.0.CO;2-U

8. M. D. Stanciu, O. M. Terciu, I.Curtu, Pro Ligno, J. Timber Engg., 9 (4), 443 (2013).

9. S. Vlase, H. T. Draghicescu, M. R. Calin, L. Serbina, Optoelectronics and Adv. Mat. 5 (4), 424 (2011).

10. F. C. Ferreira, A. A. S. Curvelo, and L. H. C. Mattoso, J. Appl. Polym. Sci. 89 (11), 2957 (2003).

11. K. Oksman and H. Lindberg, J. Appl. Polym. Sci. 68 (1), 1845 (1998). http://dx.doi.org/10.1002/(SICI)1097-4628(19980613)68:11<1845::AID-APP16>3.0.CO;2-T

12. B. Liao, Y. Huang, and G. Cong, J. Appl. Polym. Sci. 66 (1), 1561 (1997). http://dx.doi.org/10.1002/(SICI) 1097-4628(19971121)66:8<1561::AID-APP17>3.0.CO;2-6

13. M. J. Zaini, M. Y. A. Fuad, Z. Ismail, M. S. Mansor, and J. Mustafah, Polym. Intern. 40 (1) 51 (1996). http://dx.doi.org/10.1002/(SICI)1097-0126(199605)40:1<51::AID-PI514>3.0.CO;2-I

14. M. Kaci, S. Cimmino, C. Silvestre, D. Duraccio, A. Benhamida, and L. Zaidi, Macromol. Mater. Eng., 291, 869 (2006).

15. B. Xu, J. Simonsen, and W. E. Rochefort, J. Applied Polymer Science, 79 (1), 418 (2001). http://dx.doi.org/10.1002/1097-4628(20010118)79:3<418::AID-APP40>3.0.CO;2-X

16. M. Paauw, and A. Pizzi, J. Appl. Polym. Sci. 50 (1), 1287 (1993). http://dx.doi.org/10.1002/app.1993.070500720

17. G. Kranthi, A. Satapathy, J. Comp. Mat. Sci., 49, 609 (2010). http://dx.doi.org/10.1016/j.commatsci.2010.06.001

18. R. G. Raj, B.V. Kokta, and C. Daneault, J. Adhesion Sci. Technol. 3, 55 (1989).

19. Z. Mosadeghzad, I. Ahmad, R. Daik, A. Ramli and Z. Jalaludin, Malaysian Polymer Journal, 4 (1), 30 (2009).

20. S. V. Prasad, C. Pavithran and P. Rohatgi, J. Mat. Sci. 8, 1443 (1983). http://dx.doi.org/10.1007/BF01111964

21. J. Kuruvilla, T. Sabu and C. Pavithran. Polymer, 23, 5139 (1996).

22. S. Panthapulakkal, M. Sain, Composites Part A: App. Sci. and Manu., 38 (6), 1445 (2007).

23. A. Bismarck, I. A. Askargorta, J. Springer, T. Lampke, B. Wielage, A. Stamboulis, Polymer Composite 23, 872 (2002). http://dx.doi.org/10.1002/pc.10485 
24. S. Lin-Gibson, V. Baranauskas, J. S. Riffle and U. Sorathia, Polymer, 43, 7389 (2002). 2002. http://dx.doi.org/10.1016/S0032-3861(02)00538-4

25. L. R. Bao and A. F. Yee, Polymer, 43, 3987 (2002). http://dx.doi.org/10.1016/S0032-3861(02)00189-1 